\title{
Ultrasonography of desmoplatic fibroma of the mandible; a case report.
}

\author{
Mariana M. Gersak ${ }^{1}$, Lavinia M. Lenghel ${ }^{2}$, Grigore Baciut ${ }^{3}$, Iuliu Moldovan ${ }^{3}$, Horațiu Mitea ${ }^{4}$, \\ Carolina Botar-Jid², Dan Vasilescu², Emil Boțan ${ }^{5}$, Sorin M. Dudea ${ }^{2}$
}

\begin{abstract}
${ }^{1}$ Department of Radiology, Emergency County Hospital, ${ }^{2}$ Department of Radiology, University of Medicine and Pharmacy "Iuliu Haţieganu", ${ }^{3}$ Department of Cranio-Maxilo-Facial Surgery, University of Medicine and Pharmacy "Iuliu Haţieganu", ${ }^{4}$ Cranio-Maxilo-Facial Surgery Hospital, ${ }^{5}$ Department of Pathology, Emergency County Hospital, Cluj-Napoca, Romania
\end{abstract}

\begin{abstract}
Desmoplastic fibroma (DF) is a very rare bone tumor, classified as a benign lesion. It might be locally a very aggressive tumor with a high rate of recurrence after surgical resection. We present a case of a 3-year and 6 month-old patient, with mandibular desmoplastic fibroma. The clinical, imaging, histological findings and surgical treatment are discussed and, also, a brief review of the literature of DF is presented. The purpose of this case report is to emphasize the particularity of the case, ultrasound findings and the main differential diagnostic of this rare bone tumor.
\end{abstract}

Keywords: desmoplastic fibroma, mandible, ultrasound

\section{Introduction}

Desmoplastic fibroma (DF) is a benign bone tumor. It is considered to be a very aggressive tumor with a local recurrence up to $67 \%$ of the cases, after surgical resection [1]. This remarkable rare tumor $(0.11 \%$ of all primary bone tumors) is histological similar to the desmoid tumor with extra-abdominal distribution [1,2]. Between 1968 and 2011 only 18 cases of DF of the mandible, in patients younger than 4 years-old were reported [3]. For most of the reported cases, X-ray, CT and MRI appearance were described, but ultrasonographic appearance was evaluated only by Averna et al [4]. The literature describes possible metastasis of DF, but there was no clear evidence to confirm this assertion [2]. Clinically, the patients may complain of pain, swelling above the affected area or they may be completely asymptomatic. The treatment is wide surgical resection, when is possible, to prevent local recurrence.

Received 26.01.2015 Accepted 25.02.2015

Med Ultrason

2015, Vol. 17, No 3, 407-410

Corresponding author: Lavinia M. Lenghel

3-5 Clinicilor Str,

400006 Cluj-Napoca,

Phone: +40740423025

E-mail: manu_2416@yahoo.com
We present the case of a young boy with a DF evolved in the mandible, emphasizing the ultrasonographic appearance of the tumor and the particularities of the case.

\section{Case report}

A 3-year and 6 month-old boy with the initial clinical presentation of a roughly $1 \mathrm{~cm}$ right mandibular swelling was diagnosed in an outer institution with reactive lymphadenitis and treated with antibiotics. No response was obtained and the swelling continued to progress. After 8 weeks, the boy was admitted in the Department of Cranial and Maxillofacial Surgery for the diagnosis of the swelling which, at the time of the admission, measured clinically around $3 \mathrm{~cm}$ in diameter. Physical examination revealed facial asymmetry induced by a right mandibular and submandibular area swelling, unaccompanied by skin color changes or inflammation. The panoramic x-ray showed an osteolytic, trabeculated lesion localized in the body of the right mandible, with ill-defined borders (fig 1).

Ultrasound was performed in the Radiology Department. Grey-scale ultrasound revealed a $34 \mathrm{~mm}$ long, solid, hypoechoic lesion belonging to the bone, with inhomogeneous structure and ill-defined borders. The tumor had an invasive appearance in the mandible, with periosteal reaction and osseous destruction and also ex- 
tension in the neighboring soft tissues. The Doppler examination detected vessels with chaotic distribution and high impedance. Sonoelastography showed intermediate stiffness for the extraosseous part of the tumor while the intraosseous part of the lesion appeared stiffer, with the predominance of the blue pattern (fig 2).

Several right sided laterocervical and submandibular lymph nodes were found, with worrying appearance: rounded, hypoechoic, with cortical hyperplasia, well vascularized and presenting high impedance Doppler signal.

The ultrasound findings suggested the presence of a right mandibular tumor with malignant characters, associated with suspected metastatic lymph nodes.

A non-enhanced CT examination was performed in order to characterize the bony extension of the tumor. CT scan revealed a large osteolytic lesion of the mandible, with sunburnst periosteal reaction and invasion of the surrounding soft tissues (figure 6).

The CT appearence was also highly indicative of a malignant bone tumor with extension into the soft tissues (fig 3).

Surgical biopsy was taken from a lymph node and from the main lesion. The histology of the main lesion revealed proliferation of fibroblasts and collagenous stroma, without necrosis or mitotic activity (fig 4a). The lymph node presented follicular hyperplasia. The histologic diagnosis was mandibular desmoplastic fibroma associated with reactive submandibular lymph node. The treatment was surgical, with wide local resection (fig 4b).

\section{Discussions}

DF is a benign, intra-osseous desmoid tumor, locally very aggressive, associated with a high percentage of recurrence after resection. Several authors described a po-

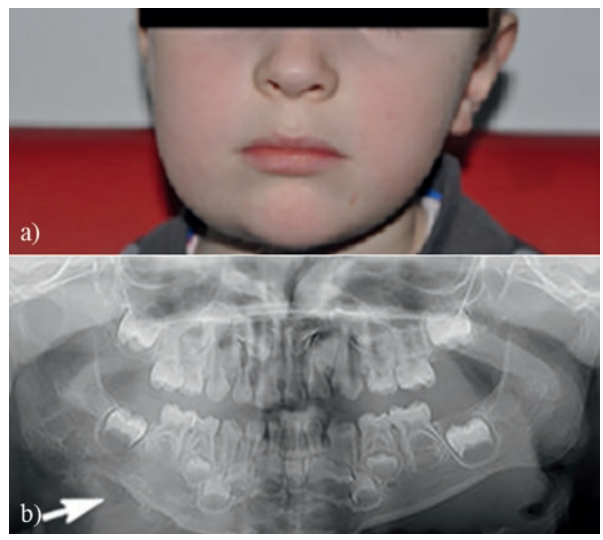

Fig 1. a) Clinical presentation: swelling of the right mandibular area; b) Panoramic X-ray: osteolytic, trabeculated lesion of the right mandible (arrow)

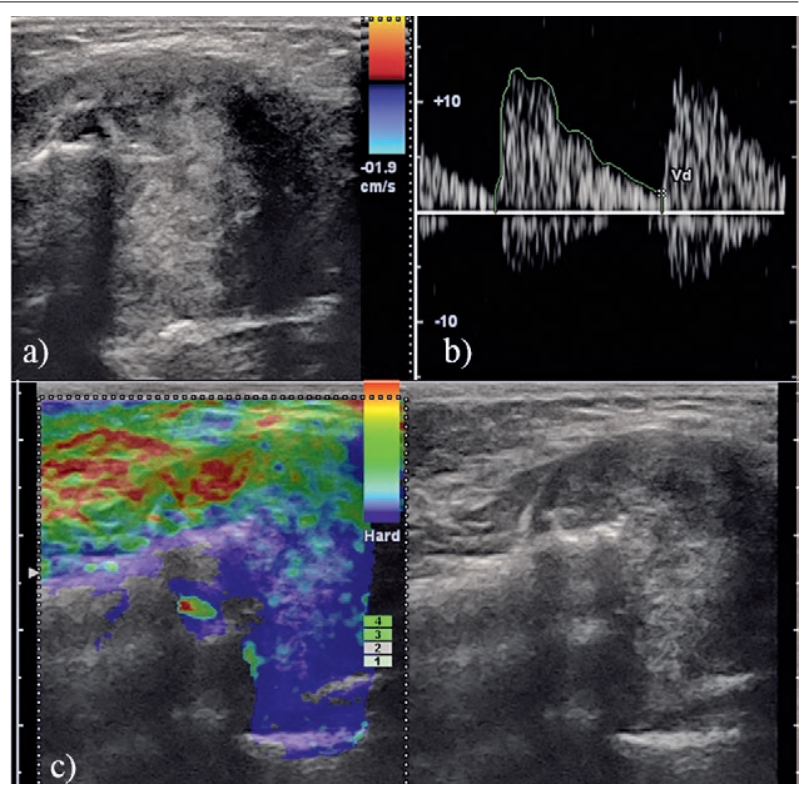

Fig 2. Ultrasonography findings of the tumor: a) Grey-scale - inhomogeneous, hypoechoic lesion with invasion of the bone and surrounding soft tissue; b) Pulsed-wave Doppler ultrasound: high impedance vessels in the tumor $(\mathrm{RI}=0.87$; $\mathrm{PI}=$ $1,56)$; c) Real-time sonoelastography of the tumor.

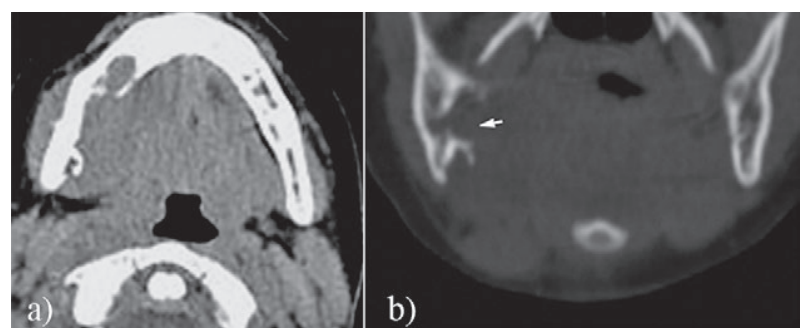

Fig 3. Axial CT scan in soft tissue window (a) and coronal CT scan (b) in bone window: large osteolytic lesion of the right mandible with sunburst periosteal reaction and cortical breakthrough.

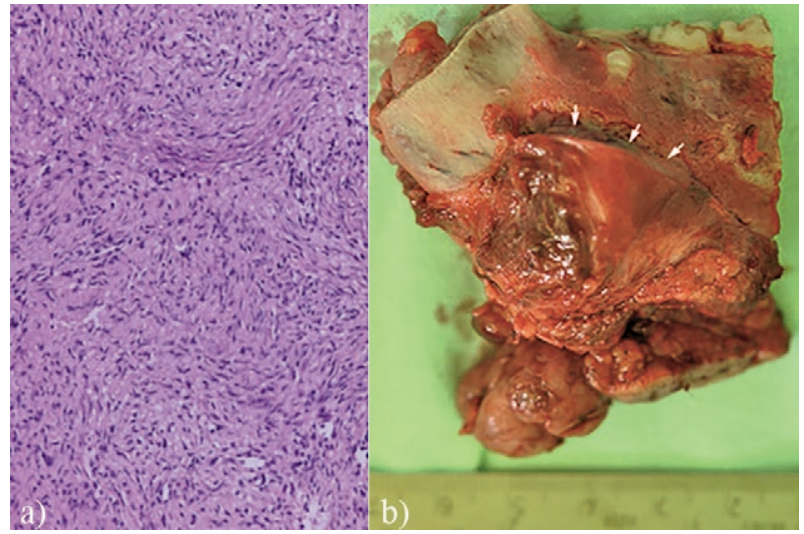

Fig 4. a) The histology of the main lesion revealed proliferation of fibroblasts and collagenous stroma, without necrosis or mitotic activity; b) Operative specimen: tumor pointed by white arrows 
tential metastatic evolution of this tumor [2,5-7]. Griffith et al [8] described in 1965 the first case of desmoplastic fibroma of the jaw. DF may appear in any bone of the human body, but it involves most often the mandible ( $22 \%$ of DF's) [2]. The occurrence of DF is mostly insidious; the patients may complain of swelling or pain above the affected area or it may be completely asymptomatic [9]. Most of the cases described in the literature were investigated by X-ray, CT and MRI examination, with only one of the reported cases having ultrasound investigation [4].

The differential diagnosis of mandibular DF includes almost any osteolytic lesion (table I). Some of the differential diagnosis may be established by imaging solely while others need complete imaging assessment and biopsy.

Radiologic findings in desmoplastic fibroma are unspecific and include osteolytic, trabeculated lesions, with partially sharp or ill-defined margins [5,9]. CT scan usually demonstrates osteolytic lesions with cortical breakthrough, slight pseudotrabeculation and bone expansion [14]. MRI best evaluates the soft tissue extension. The signal is variable with nonspecific low signal intensity on T1-weighted images and intermediate to high signal intensity on T2-weighted images [4,14-16].

The published report described the ultrasound appearance of DF as being a well-defined, highly vascular tumor, without necrotic or hemorrhagic areas [4]. In our case, complete ultrasound examination was performed, assembling grey-scale, Doppler and sonoelastograpy information about the tumor. At grey-scale, the lesion was similar to the description of Averna et al [4], but also, a discreet periosteal reaction was identified. At the same time, there were no necrotic or hemorrhagic intralesional areas. Sonoelastography displayed increased stiffness of the intraosseous portion of the tumor, although the tumor was histological homogenous, with no necrosis. This appearance may be explained both by lower strain expected on a tissue that is encased in bone and by the strain decay with distance.

Pre-operative CT scan was performed in order to obtain more information about the extension of the lesion It revealed a discreet sunburst periosteal reaction and mandibular cortical bone interruption. In most of DF cases reported, periosteal reaction was absent $[4,5,9,17]$ but in a few cases, however, a discreet sunburst periosteal reaction was noted [7,18-20].

Histologically, DF is difficult to be differentiated from the low-grade fibrosarcoma. Clear distinction between these two entities might not be always possible but the recurrence and metastasis after therapy might indicate a low-grade fibrosarcoma, as the DF evolution locally is more aggressive and does not include metastasis [21].

As treatment for DF, complete surgical resection with narrow safety margins is preferred, when possible, which was the case for our patient. Radiotherapy is used for non-

Table I. Differential ultrasound diagnosis of the desmoplastic fibroma

\begin{tabular}{|c|c|}
\hline diagnosis & Ultrasound features \\
\hline Simple bone cyst & $\begin{array}{l}\text { - anechoic lesion with posterior enhancement. } \\
\text { - thinning of the bone cortex } \\
\text { - without periosteal reaction [10] }\end{array}$ \\
\hline Giant cell t & $\begin{array}{l}\text { - hypoechoic, homogeneous, intraosseous tumor, with hypoechoic areas } \\
\text { - the cortex is thin or completely disrupted with extraosseous tumor mass }\end{array}$ \\
\hline $\begin{array}{l}\text { Metastasis of adeno- } \\
\text { carcinomas }\end{array}$ & $\begin{array}{l}\text { - homogeneous/heterogeneous hypo echoic soft tissue mass } \\
\text { - well-defined margins } \\
\text { - bone destruction [10] }\end{array}$ \\
\hline Aneurysmal bone cyst & $\begin{array}{l}\text { - hypoechoic, well-delimitated and vasculated lesion } \\
\text { - the cortex reduced to a thin bone shell, sometimes completely interrupted. } \\
\text { - typically- hyperechogenic fluid-fluid levels [11] }\end{array}$ \\
\hline Hemangioma & $\begin{array}{l}\text { - typically appear as masses of mixed echogenicity with low-resistance Doppler arterial signals [11] } \\
\text { Includes } 4 \text { possible patterns: }\end{array}$ \\
\hline Ameloblastoma & $\begin{array}{l}\text { 1. multilocular- variable size areas, conglomerated, usually with elliptical shape, with many strong } \\
\text { echo bands } \\
\text { 2. honeycomb- small compartments with irregular bony septa. } \\
\text { 3. unilocular- well-defined, without bony septum echo band inside the lesion } \\
\text { 4. local severe destructive- ill-defined, with local invasion of the bony matrix, with uneven internal } \\
\text { echoes } \\
\text { - Doppler signal - variable- correlated with proliferation of the tumor- absent, minimal, moderate or } \\
\text { abundant vascular signal } \\
\text { - the cortex of the bone- thin but continue or destructed [12] }\end{array}$ \\
\hline Condromixoid fibroma & $\begin{array}{l}\text { - well-defined hypoechoic lesion, with echoic and anechoic areas } \\
\text { - scattered Doppler signal } \\
\text { - might be osteolytic, with or without periosteal reaction }[10,13]\end{array}$ \\
\hline
\end{tabular}


resectable tumors and chemotherapy for patients with limited possibilities of local resection $[7,22]$. The recurrence rate is up to $67 \%$ [1]. Our patient was reassessed at 3 and 8 months after the surgical procedure with MRI and ultrasound and no local or nodal recurrence was found.

In conclusion, the non-specific clinical appearance of the DF implies an extensive imaging study before in order to establish a proper therapeutic approach. Although ultrasound has a limited contribution for intra-osseous extension of the tumor, in cases when ultrasound is the first imaging method of evaluation, the presence of a DF must be taken in account.

\section{References}

1. Stefanidis K, Benakis S, Tsatalou E, Ouranos V, Chondros D. Computed tomography and magnetic resonance imaging of desmoplastic fibroma with simultaneous manifestation in two unusual locations: a case report. J Med Case Rep 2011; 5: 28.

2. Nedopil A, Raab P, Rudert M. Desmoplastic fibroma: a case report with three years of clinical and radiographic observation and review of the literature. Open Orthop J 2013; 8: 40-46.

3. Ferri A, Leporati M, Corradi D, Ferri T, Sesenna E. Huge desmoplastic fibroma of the paediatric mandible: surgical considerations and follow-up in three cases. J Craniomaxillofac Surg 2013; 41: 367-370.

4. Averna R, De Filippo M, Ferrari S, Bacchini E, Rossi C. Desmoplastic fibroma of the mandible. Acta Biomed 2011; 82: 69-73.

5. Schneider M, Zimmermann AC, Depprich RA, et al. Desmoplastic fibroma of the mandible - review of the literature and presentation of a rare case. Head Face Med 2009; 5: 25.

6. Jaffe HL. Desmoplastic fibroma and fibrosarcoma. In: Jaffe HL (ed). Tumors and tumorous conditions of the bones and joints. Lea and Febiger; Philadelphia, PA 1958: 298-303.

7. Gebhardt MC, Campbell CJ, Schiller AL, Mankin HJ. Desmoplastic fibroma of bone. A report of eight cases and review of the literature. J Bone Joint Surg Am 1985; 67: 732-747.

8. Griffith JG, Irby WB. Desmoplastic fibroma. Report of a rare tumor of the oral structures. Oral Surg Oral Med Oral Pathol 1965; 20: 269-275.
9. Bakaeen G, Rajab LD. Desmoplastic fibroma of the mandible: report of a case. Int J Paediatr Dent 1999; 9: 117-121.

10. Bin K, Jingyuan D, Jianhua H. Sonographic Diagnosis of Bone Tumors. Journal of Tongji Medical University 1997; 17: 106-109.

11. Gomez J, Pinar A, Vallcanera A, Moreno A, Cortina H. Sonographic findings in aneurysmal bone cyst in children: correlation with computed tomography findings. J Clin Ultrasound 1998; 26: 59-64.

12. Lu L, Yang J, Liu JB, Yu Q, Xu Q. Ultrasonographic evaluation of mandibular ameloblastoma: a preliminary observation. Oral Surg Oral Med Oral Pathol Oral Radiol Endod 2009; 108: e32-e38.

13. Marin C, Gallego C, Manjon P, Martinez-Tello FJ. Juxtacortical chondromyxoid fibroma: imaging findings in three cases and a review of the literature. Skeletal Radiol 1997; 26: 642-649.

14. Urresola A, Sáez F, Canteli B, Elorriaga R, López-Duque JC. Desmoplastic fibroma of bone: a report of two cases. Radiologia 2007; 49: 205-210.

15. Vanhoenacker FM, Hauben E, De Beuckeleer LH, Willemen D, Van Marck E, De Schepper AM. Desmoplastic fibroma of bone: MRI features. Skeletal Radiol 2000; 29: 171-175.

16. Desmoplastic fibroma. OrthopaedicsOne - The Orthopaedic Knowledge Network. Created 2010 Jun 12. Last modified 2011 Nov 03 ver.3. Retrieved 2013 Oct 22. http://www.orthopaedicsone.com $/ \mathrm{x} / \mathrm{lw} 0 \mathrm{CAg}$.

17. Celli P, Cervoni L, Trillo G. Desmoplastic fibroma of the skull. Case report and review of the literature. Neuro Chir 1997; 43: 260-264

18. Crim JR, Gold RH, Mirra JM, Eckardt JJ, Bassett LW. Desmoplastic fibroma of bone: radiographic analysis. Radiology 1989; 172: 827-832.

19. Shi H, Wang P, Wang S, Yu Q. Desmoplastic fibroma of the mandible. Dentomaxillofac Radiol 2008; 37: 408-411.

20. Taconis WK, Schütte HE, van der Heul RO. Desmoplastic fibroma of bone: a report of 18 cases. Skeletal Radiol 1994; 23: $283-288$.

21. Inwards CY, Unni KK, Beabout JW, Sim FH. Desmoplastic fibroma of bone. Cancer 1991; 68: 1978-1983.

22. Altmann S, Lenz-Scharf O, Schneider W. Therapeutic options for aggressive fibromatosis. Handchir Mikrochir Plast Chir 2008; 40: 88-93. 